\title{
Green Tea Product Epigallocatechin Gallate (EGCG) Content and Label Information: A Descriptive Analysis
}

\author{
Marina V. Shkayeva*, Philip J. Gregory, Matthew K. Pickering, Darren J. Hein, James Hu \\ and Aleah Rodriguez
}

Therapeutic Research Center (MS, PG), Creighton University Center for Drug Information \& Evidence-Based Practice (PG, DH, JH, AR), University of Maryland School of Pharmacy, USA

\begin{abstract}
Green tea's popularity can be largely attributed to its potential health benefits, with an emphasis on antioxidant properties from its catechin constituents, especially (-)-epigallocatechin-3-gallate (EGCG). EGCG appears to be responsible for many of the potential health benefits of green tea. However, while higher intake levels may provide benefit, lower intake levels may not. The objective was to determine whether commercially available green tea products provide label information about EGCG content and other constituents and then to analyze the label information in terms of existing research. A descriptive analysis of product label information was conducted. In total, 105 green tea products evaluated, $58 \%$ of green tea supplements and $5 \%$ of green tea beverages included information about EGCG content on the label. Among the dietary supplement products providing sufficient information on the label, the amount of EGCG listed ranged from $70 \mathrm{mg}$ to $600 \mathrm{mg}$ per serving. The average EGCG per serving was $223.7 \mathrm{mg}$. The average reported caffeine content was $56.0 \mathrm{mg}$ per serving. In conclusion, most green tea beverages to not provide adequate information about EGCG or other constituents. Green tea supplements are more likely to provide this information. One to two servings of green tea supplements are typically needed to achieve EGCG or catechin intake levels similar to those demonstrating efficacy in clinical studies. Consumers should consider selecting products that adequately describe constituent information on the label. Manufacturers should consider providing this essential information on the product label in order to better inform consumer decision-making.
\end{abstract}

Keywords: Nutraceutical, green tea, catechins, EGCG, supplement labeling.

\section{INTRODUCTION}

Tea is obtained from the leaves and buds of the Camellia sinensis plant. There are several different forms of tea including green, black, pu-erh, and oolong or white tea [1,2]. How the Camellia sinensis plant parts are grown, harvested, and processed will determine the form obtained.

There has been particular interest in green tea due to health benefits associated with its consumption. In large part, these benefits have been attributed to green tea's high concentration of catechins, specifically the major catechin, (-)-epigallocatechin-3-gallate (EGCG) $[3,4]$. Notably, EGCG makes up about $60 \%$ of the total catechins in green tea [5].

The Tea Association of the U.S.A. Inc. reports that in 2014, Americans consumed over 80 billion servings of tea, total imported tea was worth 10.8 billion dollars, and green tea sales have grown $60 \%$ in volume over the past 10 years [6].

Clinical studies have been conducted evaluating the effects of EGCG and green tea catechins in conditions such as cancer, hyperlipidemia, diabetes, and many

*Address correspondence to this author at the Therapeutic Research Center, 1 Davis Square, Somerville, MA 02144, USA; Tel: (617) 591-3316;

E-mail: mshkayeva@gmail.com more [5,7-10]. No consensus on an optimal EGCG dose or intake level currently exists; however, evidence suggests that higher green tea catechin levels and specifically EGCG are needed for therapeutic effects. A meta-analysis of 20 randomized controlled trials evaluating the effect green tea catechins on lipid levels reported that green tea intake ranged from 145-3000 $\mathrm{mg} /$ day. EGCG doses ranged from 68-1037.8 mg/day. Subgroup analysis found that $200 \mathrm{mg}$ of EGCG or more was necessary to decrease total cholesterol and low-density lipoprotein (LDL) cholesterol levels. Lower intake levels had no effect [8]. In another pooled analysis, a higher green tea catechin intake ( $\geq 457$ $\mathrm{mg} /$ day) resulted in significant decreases in fasting blood glucose in diabetic subjects, while a lower intake had no effect [9]. In a randomized controlled study, $750-1000 \mathrm{mg} / \mathrm{m}^{2}$ of green tea extract (corresponding to a higher plasma level of EGCG) increased clinical response in patients with high-risk oral premalignant lesions. Again, lower intake levels of green tea extract, $0-500 \mathrm{mg} / \mathrm{m}^{2}$ (and subsequent lower blood levels of free EGCG) had no effect [10]. These data suggest that higher intake levels of green tea catechins, specifically EGCG, are more likely to result in therapeutic effects.

In addition to health benefits, some potential harms may be associated with EGCG intake levels. Preliminary research in animals showed that oral doses ranging from $500-1500 \mathrm{mg} / \mathrm{kg}$ of EGCG caused 
increases in biochemical markers for liver injury as well as moderate to severe hepatotoxicity $[11,12]$. Based on allometric scaling, an equivalent human dose would be $30-90 \mathrm{mg} / \mathrm{kg}$ [11]. Several cases of green tea-related hepatotoxicity have also been reported. However, causality is difficult to assess in many of these reports [13]. Clinical research in humans has found that EGCG at doses of $800 \mathrm{mg}$ and $1600 \mathrm{mg}$ do not adversely affect the liver $[14,15]$.

Given the important role of EGCG in the potential health benefits and harms of green tea, it is important for green tea consumers and healthcare practitioners to be able to recognize the amount of EGCG in commercially available green tea products.

This analysis was undertaken in order to evaluate and characterize the labelled amounts of EGCG and other contents of commercially available green tea products.

\section{METHODS}

In order to identify commercially available green tea products, a systematic search was conducted using Google and Bing search engines, as well as the Google and Bing shopping services from January $25^{\text {th }}$ to January $29^{\text {th }}, 2013$. The search terms used were "green tea" in combination with one of the following: "capsule", "tablet", "pill", "extract", "drink", "beverage", "leaf", "powder", or "matcha powder". Commercially available single-ingredient green tea or green tea with caffeine products were included if they were ingestible dietary supplements or beverages. Decaffeinated and flavored products were also included. Products in which green tea did not appear to be the main ingredient were excluded.

For each product identified, label information was characterized including brand and manufacturer, green tea form (e.g., extract, powder, tablet, or capsule), strength or concentration, and the amounts of EGCG, catechins, caffeine, and polyphenols, if provided. In addition, dosing instructions and serving sizes were tabulated.

\section{RESULTS}

The systematic search identified 105 green tea products. Of these, $54(51 \%)$ were brewable tea beverages, $45(43 \%)$ were dietary supplements (tablets or capsules). The remaining six were non-brewable tea beverages.
Of the 60 tea beverages identified, only $3(5 \%)$ reported EGCG content. In these products the average EGCG per serving was $94.3 \mathrm{mg}$ (range: $83-100 \mathrm{mg}$ ).

Caffeine content was provided for 19 of 60 (32\%) green tea beverages identified. Average caffeine content per serving was $29.6 \mathrm{mg}$ (range: $4-72.5 \mathrm{mg}$ ).

For green tea-containing dietary supplement products, 37 out of $45(82 \%)$ reported the amount of green tea extract. The average was $584.2 \mathrm{mg}$ per serving (range: 100-1950 mg).

EGCG content was provided for 26 out of $45(58 \%)$ dietary supplement products. The average EGCG per serving was $223.7 \mathrm{mg}$ (range: 70-600 mg). Additionally, 17 out of $45(38 \%)$ products reported catechin content. The average catechin content was $357.8 \mathrm{mg}-$ per serving (range: $125-700 \mathrm{mg}$ ). Thirty out of $45(67 \%)$ reported total polyphenol content with the average being $347.3 \mathrm{mg}$ per serving (range: $95-800 \mathrm{mg}$ ).

Caffeine content was reported for 16 out of 45 $(36 \%)$ green tea dietary supplement products. The average reported caffeine content was $56.0 \mathrm{mg}$ per serving (range: 0-160 mg).

For green tea-containing dietary supplement products, labelled dosing recommendations ranged from 1 to 3 servings daily. Based on these recommendations, average daily EGCG intake would be $273 \mathrm{mg}$ (range: $75-600 \mathrm{mg}$ ). Average daily caffeine intake would be $76.8 \mathrm{mg}$ (range: 0-320 mg).

\section{DISCUSSION}

These data show that green tea beverages rarely describe the EGCG or caffeine content of the product on their labels. Green tea-containing dietary supplements are much more likely to provide this information on the product label compared to beverages, but still only $58 \%$ of these products reported EGCG content and only $36 \%$ reported caffeine content.

Green tea beverage products that were assessed contained less than half of the EGCG content per serving of green tea dietary supplements products.

Some previous clinical research found that EGCG intake of at least $200 \mathrm{mg}$ or total catechin intake of at least $457 \mathrm{mg}$ was necessary for therapeutic effects $[8,9]$. In most cases, two or more green tea beverage servings would be needed to achieve this EGCG intake 
level. For green tea dietary supplements, a single serving would achieve adequate EGCG intake in most cases. However, more than one serving would usually be needed to achieve total catechin intake above 450 $\mathrm{mg}$. Green tea dietary supplement labelling typically recommends $1-3$ servings per day.

For dietary supplement products, label information regarding caffeine content suggests that most products are not likely to provide a dangerous amount of caffeine if the suggested dosing schedules are followed. Caffeine poisoning can occur at an intake of $10 \mathrm{mg} / \mathrm{kg}$ (about $750 \mathrm{mg}$ ) as a single dose, but the dose can vary based on the person's pre-existing tolerance or sensitivity to caffeine [16]. The FDA states that $400 \mathrm{mg}$ caffeine per day is safe to consume for adults $[18,19]$. The range of caffeine intake based on average caffeine content and typically recommended serving amounts in the assessed green tea products is between zero and $320 \mathrm{mg}$ daily. Consumers should take caution that the total amount of caffeine consumed throughout the day from different sources does not exceed $400 \mathrm{mg}$.

Our findings are similar to the findings of ConsumerLab.com, an organization that independently tests the content of dietary supplement products. ConsumerLab.com identified six green tea products which were tested and verified to contain an average of $188 \mathrm{mg}$ EGCG per serving (range 75-326.25 mg) [17]. This EGCG content is lower than our finding of an average $223.7 \mathrm{mg}$ EGCG content per serving (range: $70-600 \mathrm{mg})$.

\section{LIMITATIONS}

The findings of this study are limited in several ways. First, our search was limited to products advertised or available for purchase online. We identified 105 single-ingredient green tea products. The complete marketplace likely includes more than 105 products. However, we believe our sample is likely a fair representation of the broader market.

Additionally, we only evaluated the product content as stated on the label. The actual product content may vary substantially from what is reported on the label.

There is no current consensus about an adequate intake level of green tea catechins for therapeutic benefits. Therefore, accurate conclusions regarding whether commercially available green tea products provide an appropriate amount of green tea catechins, specifically EGCG, cannot be currently made.

\section{CONCLUSION}

Most great tea beverages and many green tea dietary supplements do not adequately report EGCG or caffeine content on the product label. EGCG is thought to be largely responsible for the health benefits from green tea. Patients who are interested in taking green tea for potential health benefits should seek out products that adequately report EGCG content on their label. Products that do not adequately report this information should be avoided.

Although manufacturers are not required to report levels of constituents in their product labeling, doing so would enhance consumers' ability to select an appropriate product to meet their health needs. Many standardized herbal extracts report constituent information on the product label. For example, standardized extracts of St. John's wort typically report the concentration of hypericin or hyperforin. Valerian extracts sometimes report valerenic acid concentration. Green tea product manufacturers should consider this approach to improve their labeling.

\section{REFERENCES}

[1] Rietveld A, Wiseman S. Antioxidant effects of tea: evidence from human clinical trials. J Nutr 2003; 133: 3275-84.

[2] McKay DL, Blumberg JB. The role of tea in human health: An update. J Am Coll Nutr 2002; 21: 1-13 http://dx.doi.org/10.1080/07315724.2002.10719187

[3] Riegsecker S, Wiczynski D, Kaplan MJ, Ahmed S. Potential benefits of green tea polyphenol EGCG in the prevention and treatment of vascular inflammation in rheumatoid arthritis. Life Sciences 2013; 93(8): 307-12. http://dx.doi.org/10.1016/j.Ifs.2013.07.006

[4] Zuo $Y$, Chen $H$, Deng $Y$. Simultaneous determination of catechins, caffeine and gallic acids in green, Oolong, black and pu-erh teas using HPLC with a photodiode array detector. Talanta 2002; 57(2): 307-16. http://dx.doi.org/10.1016/S0039-9140(02)00030-9

[5] Bettuzzi S, Brausi M, Rizzi F, Castagnetti G, Peracchia G Corti A. Chemoprevention of human prostate cancer by ora administration of green tea catechins in volunteers with highgrade prostate intraepithelial neoplasia: a preliminary report from a one-year proof-of-principle study. Cancer Res 2006; 66(2): 1234-40.

http://dx.doi.org/10.1158/0008-5472.CAN-05-1145

[6] Teausa [homepage on the Internet]. Tea Fact Sheet 2014. New York, NY: TeaUSA, Inc.; c2013 [cited 2013 March 1]. Available from: http://www.teausa.com/14655/tea-fact-sheet.

[7] Clement Y. Can green tea do that? A literature review of the clinical evidence. Preventative Med 2009; 49(2-3): 83-87. http://dx.doi.org/10.1016/j.ypmed.2009.05.005

[8] Kim A, Chiu A, Barone MK, Avino D, Wang F, Coleman Cl, et al. Green tea catechins decrease total and low-density lipoprotein cholesterol: a systematic review and metaanalysis. J Am Diet Assoc 2011; 111(11): 1720-9. http://dx.doi.org/10.1016/j.jada.2011.08.009

[9] Liu K, Zhou R, Wang B, Chen K, Shi LY, Zhu JD, et al. Effect of green tea on glucose control and insulin sensitivity: a 
meta-analysis of 17 randomized controlled trials. Am J Clin Nutr 2013; 98(2): 340-8.

http://dx.doi.org/10.3945/ajcn.112.052746

[10] Tsao AS, Liu D, Martin J, Tang XM, Lee JJ, El-Naggar AK, et al. Phase II randomized, placebo-controlled trial of green tea extract in patients with high-risk oral premalignant lesions. Cancer Prev Res (Phila Pa) 2009; 2(11): 931-941. http://dx.doi.org/10.1158/1940-6207.CAPR-09-0121

[11] Lambert J, Kennett MJ, Sang S, Reuhl KR, Ju J, Yang CS. Hepatotoxicity of high oral dose (-)-epigallocatechin-3-gallate in mice. Food Chem Toxicol 2010; 48(1): 409-16. http://dx.doi.org/10.1016/j.fct.2009.10.030

[12] Wu K, Yao J, Boring D. Green tea extract-induced lethal toxicity in fasted but not in nonfasted dogs. Int $\mathrm{J}$ Toxicol 2011; 30(1): 19-20. http://dx.doi.org/10.1177/1091581810387445

[13] Sarma DN, Barrett ML, Chavez ML, Gardiner P, Ko R, Mahady GB, et al. Safety of green tea extracts: a systematic review by the US Pharmacopeia. Drug Saf 2008; 31(6): 46984.

http://dx.doi.org/10.2165/00002018-200831060-00003

[14] Chow H, Cai Y, Hakim IA, Crowell JA, Shahi F, Brooks CA, et al. Pharmacokinetics and safety of green tea polyphenols after multiple-dose administration of epigallocatechin gallate and polyphenon $\mathrm{E}$ in healthy individuals. Clin Cancer Res 2003; 9(9): 3312-9.

[15] Ullmann U, Haller J, Decourt JP, Girault N, Girault J, Richard-Caudron AS, et al. A single ascending dose study of epigallocatechin gallate in healthy volunteers. J Int Med Res 2003; 31(2): 88-101. http://dx.doi.org/10.1177/147323000303100205

[16] Fitz Simmons CR, Kidner N. Caffeine toxicity in a bodybuilder. J Accid Emerg Med 1998; 15(3): 196-197. http://dx.doi.org/10.1136/emj.15.3.196

[17] Consumerlab [homepage on the Internet]. Product Review: Green Tea Supplements, Drinks, and Brewable Teas Review. c2015 [updated 2015 January 16; cited 2015 March 1]. Available from: https: //www.consumerlab.com/reviews/ Green_Tea_Review_Supplements_and_Bottled/Green_Tea/.

[18] Nawrot P, Jordan S, Eastwood J, Rotstein J, Hugenholtz A Feeley M. Effects of caffeine on human health. Food Addit Contam 2003; 20(1): 1-30. http://dx.doi.org/10.1080/0265203021000007840

[19] FDA to Investigate Added Caffeine. FDA For Consumers: Consumer Updates. c2013 [updated 2013 May 3; cited 2015 March 1]. Available from: http: //www.fda.gov/forconsumers/ consumerupdates/ucm 350570.htm

\section{DOI: http://dx.doi.org/10.6000/1929-5634.2015.04.03.2}

(C) 2015 Shkayeva et al.; Licensee Lifescience Global.

This is an open access article licensed under the terms of the Creative Commons Attribution Non-Commercial License (http://creativecommons.org/licenses/by-nc/3.0/) which permits unrestricted, non-commercial use, distribution and reproduction in any medium, provided the work is properly cited. 